\title{
Pruritic, serpiginous eruption in a returning traveller
}

A 28-year-old woman presented with a pruritic, erythematous and serpiginous eruption on her lower back that appeared 1 week after returning from travel in Thailand (Figure 1). The results of laboratory tests (complete blood count, renal and hepatic function, and erythrocyte sedimentation rate) were normal. Results of a skin biopsy showed a cavity in the epidermis and a perivascular and periadnexal inflammatory infiltrate composed predominantly of eosinophils (Figure 2).

\section{What is the diagnosis?}
a. Scabies
b. Erythema chronicum migrans
c. Cutaneous larva migrans
d. Tinea corporis
e. Cutaneous myiasis

See page 52 for the diagnosis.

CMAJ invites submissions to "What's your call?" Clinical details (including images) are presented on the first page along with a multiple-choice question about the diagnosis. The answer and a brief discussion of the condition follow on the second page. We specifically invite submissions illustrating common or important radiographic and electrocardiographic diagnoses of appeal to a more general audience. We allow up to 5 references and require authors to obtain consent from the patient for publication of his or her story (form available at www.cmaj.ca/authors/checklist.shtml). Submit manuscripts online at http://mc.manuscriptcentral .com/cmaj.

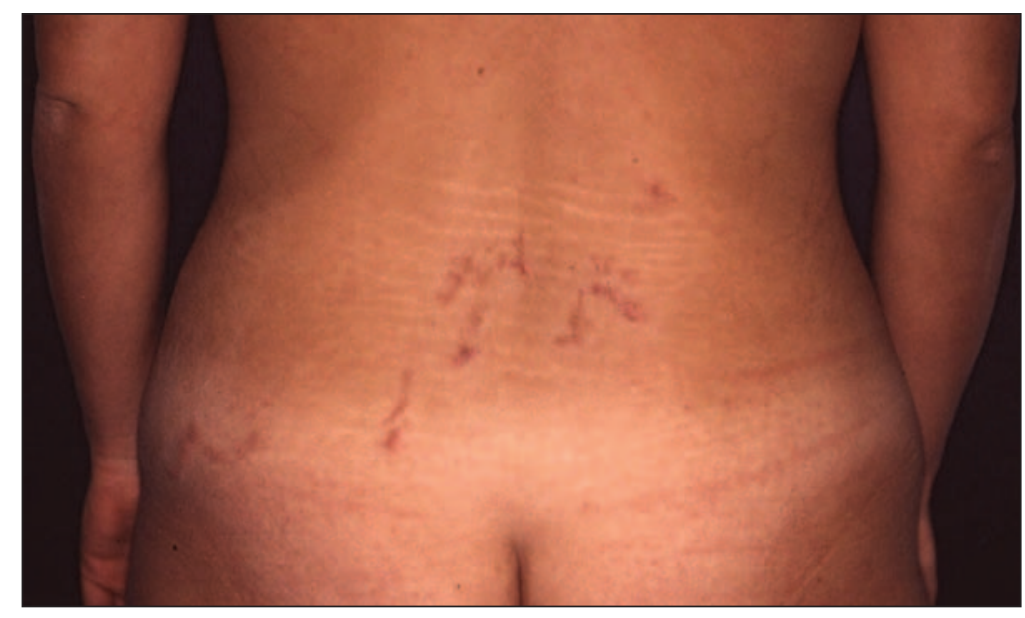

Figure 1: Pruritic, erythematous and serpiginous eruption on the lower back of a 28-year-old woman.

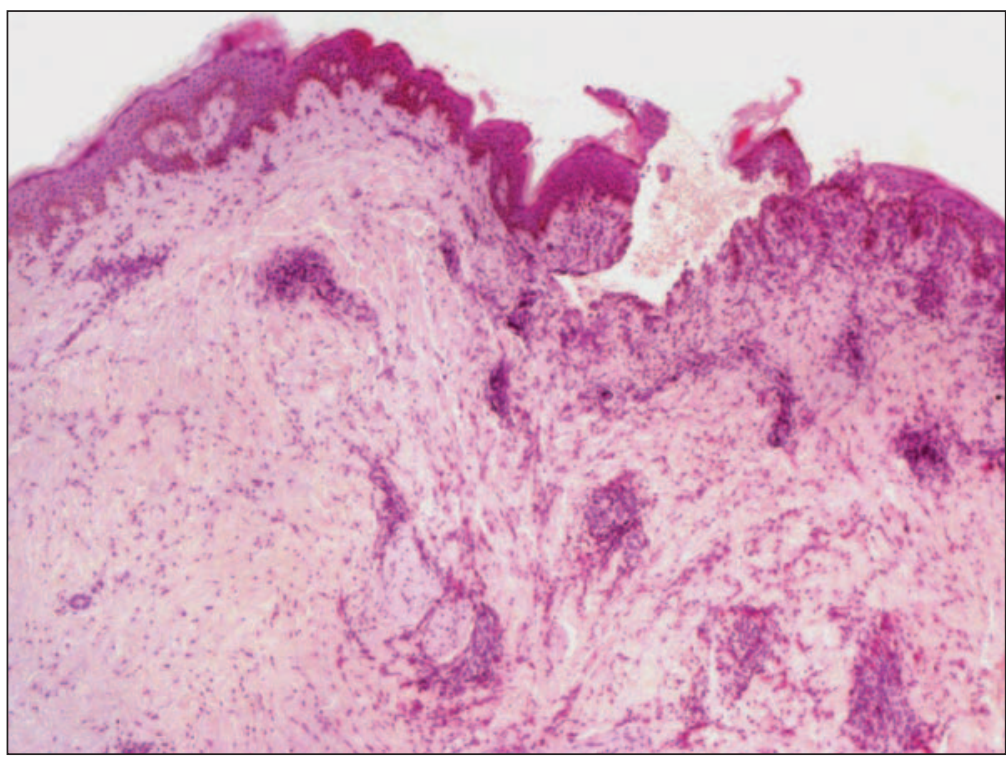

Figure 2: Biopsy specimen showing a cavity in the epidermis as well as perivascular and periadnexal inflammatory infiltrate composed predominantly of eosinophils (hematoxylin-eosin stain, original magnification $\times 2$ ). 
WHAT IS YOUR CALL?

\section{Discussion}

On the basis of the biopsy results and the patient's travel history, the answer is (c) cutaneous larva migrans, a creeping eruption due to penetration and migration of a nematode larva within the epidermis. Infestation typically occurs through contact with soil or sand contaminated with animal feces. ${ }^{1-3}$ The condition is found worldwide but occurs most frequently in warmer climates (e.g., Africa, Southeast Asia, and Central and South America). Owing to greater mobility and travel, infestations are more frequently observed now than in the past.

Symptoms, which commonly manifest in returning travellers, consist of intensely pruritic, erythematous, edematous, vesicular, linear or serpiginous tracts up to $3 \mathrm{~mm}$ wide and $20 \mathrm{~cm}$ in length. Because the incubation period varies from minutes to days or weeks, it is not always possible to determine the exact time of infection.

The lesions are localized mainly on the upper and lower extremities, which are the most exposed sites for the larva to penetrate. Additional sites include the buttocks, trunk, abdomen and, rarely, the face or perianal area. Excoriation, superimposed bacterial infections and allergic reactions are common side effects. Vesicles and bullae may develop in patients who were previously exposed.

Although the parasite usually remains confined to the epidermis, it may progress beyond the skin and cause Loeffler syndrome (migratory pulmonary infiltrates and peripheral eosinophilia). More commonly, there may be a transient moderate peripheral eosinophilia.

Cutaneous larva migrans should be suspected in patients who present with serpiginous skin lesions after returning from travel to a tropical or subtropical climate. Although it is unusual to identify the nematode, a skin biopsy shows cavities left by the parasite in the epidermis, as observed in the biopsy from our patient. Intraepidermal vesicles containing some eosinophils and a diffuse spongiosis can be also observed. In the dermis, an inflammatory infil-

Table 1: Selected differential diagnosis of cutaneous larva migrans

\begin{tabular}{ll}
\hline Condition & \multicolumn{1}{c}{ Characteristics } \\
\hline Scabies & $\begin{array}{l}\text { Erythematous papules, linear burrows and excoriation; } \\
\text { most commonly located between fingers and toes and on } \\
\text { wrist, axillae and genitalia }\end{array}$ \\
\hline $\begin{array}{l}\text { Erythema chronicum } \\
\text { migrans }\end{array}$ & $\begin{array}{l}\text { Circular erythema; follows infection with Borrelia } \\
\text { burgdorferi from tick bite; bites most commonly are found } \\
\text { on the lower extremities }\end{array}$ \\
\hline $\begin{array}{l}\text { Cutaneous larva } \\
\text { migrans }\end{array}$ & $\begin{array}{l}\text { Erythematous, serpiginous eruption associated with } \\
\text { intense pruritus; located on extremities, trunk and } \\
\text { buttocks }\end{array}$ \\
\hline Tinea corporis & $\begin{array}{l}\text { Cutaneous lesions spread centrifugally with central } \\
\text { clearing; shapes include arcs, rings and meshes, but } \\
\text { typically lesions are circular with an erythematous and } \\
\text { vesicular border; located on trunk and extremities }\end{array}$ \\
\hline Cutaneous myiasis & $\begin{array}{l}\text { Boil-like lesions from infestation by fly larvae; located on } \\
\text { trunk, extremities, buttocks, scalp and face }\end{array}$ \\
\hline
\end{tabular}

trate can be seen that is composed of lymphocytes, plasma cells, hystiocytes and numerous eosinophils.

Differential diagnosis: The clinical differential diagnosis of cutaneous larva migrans includes scabies, erythema chronicum migrans, tinea corporis, larva currens, myiasis and other nematode infestations (Table 1). ${ }^{1-3}$

Scabies is caused by the Sarcoptes scabiei mite. Its distinguishing characteristic is the burrow, which represents the tunnel that the parasite excavates while laying eggs. Lesions typically consist of erythematous papules clustered in groups, linear burrows and excoriations associated with intense pruritus. Vesicles, indurated nodules, eczematous dermatitis and superimposed bacterial infection are common.

Erythema chronicum migrans is a circular erythema caused by the bacteria Borrelia burgdorferi, which is transmitted by various ticks of the Ixodes genus. The erythema slowly migrates from the site of bite and spreads centrifugally to form ringed, arcuate or polycyclic figures.

Tinea corporis is a dermatophyte infection characterized by cutaneous lesions that spread centrifugally with central clearing. The clinical presentation depends on the causative pathogen and the immune response of the host. The lesions come in a variety of shapes, such as arcs, rings and meshes, but they are typically circular with an erythematous and vesicular border. The lesions can mimic other dermatologic conditions.

Cutaneous myiasis is the infestation of skin by fly larvae that causes boillike lesions. The larvae may be fixed to one site or may migrate, simulating larva migrans. Ultrasound and biopsy can assist in the diagnosis by determining the size of the larva.

Although cutaneous larva migrans is a self-limited infection, systemic or topical thiabendazole therapy is the first line of treatment. Cryotherapy, ivermectin and albendazole can also be used. ${ }^{4,5}$

\section{Tamara Micantonio MD Ketty Peris MD}

Department of Dermatology

University of L'Aquila

L'Aquila, Italy

This article has been peer reviewed.

Competing interests: None declared.

\section{REFERENCES}

1. Leicht SS, Youngberg GA. Cutaneous larva migrans. Am Fam Physician 1987;35:163-8.

2. Davies HD, Sakuls P, Keystone JS. Creeping eruption. A review of clinical presentation and management of 60 cases presenting to a tropical disease unit. Arch Dermatol 1993;129:588-91.

3. Brenner MA, Patel MB. Cutaneous larva migrans: the creeping eruption. Cutis 2003;72:111-5.

4. Blackwell V, Vega-Lopez F. Cutaneous larva migrans: clinical features and management of 44 cases presenting in the returning traveller. $\mathrm{BrJ}$ Dermatol 2001;145:434-7.

5. Van den Enden E, Stevens A, Van Gompel A. Treatment of cutaneous larva migrans. $N$ Engl $J$ Med 1998;339:1246-7. 